\title{
Reduction of first-year survival threatens the viability of the Mariana Crow Corvus kubaryi population on Rota, CNMI
}

\author{
JAMES C. HA, ALYSSA BUTLER and RENEE ROBINETTE HA
}

\begin{abstract}
Summary
The Mariana Crow Corvus kubaryi is a species of forest crow originally found only on the adjacent islands of Guam and Rota in the Mariana Islands of the western Pacific Ocean. Rapid and continuing declines led to it being listed by IUCN as "Critically Endangered" in 2008. Using 97 birds marked and resighted over the course of a 21 year period, we showed there was a rapid decline in first-year (fledgling to one year old) survival from 0.7 to 0.4 between 1990 and 2010 , representing a doubling in mortality, and a smaller reduction in adult survival from 0.86 to 0.82 over the same period. A population model based on Leslie matrices incorporated the effects of catastrophic events, such as typhoons and human nest removal for captive breeding. All simulations predicted a precipitous decline in future populations and the inclusion of nest removals only shortened the life of the wild population by a few years. Identifying the underlying processes behind the decline in survival is the key research priority and, given the inevitable likelihood of a continuing rapid decline, conservation action should focus on securing the future of the species through captive breeding or captive rearing of wild-born chicks and ensuring that an adaptive management conservation programme is focused on countering the factors (e.g. predation) that are currently thought to impact first-year survival and productivity. Future research may identify other causes behind the Mariana Crow's decline and the conservation programme should be flexible enough to adapt to changing needs.
\end{abstract}

\section{Introduction}

The Northern Mariana Islands are an important biodiversity hotspot, hosting a number of endemic and restricted range bird species and 15 globally threatened species, including five listed as "Critically Endangered" (BirdLife International 2010). The Mariana Crow Corvus kubaryi is a species of forest crow originally found only on the adjacent islands of Guam and Rota in the Mariana Islands of the western Pacific Ocean. The population has undergone a dramatic decline since the 1980s (Amar et al. 2008) and the extirpation of the population on Guam is associated with the introduced Brown Tree Snake Boiga irregularis (Savidge 1987). Between 1982 and 1998, there was similar decline of $82 \%$ in the crow population on Rota which by 2004 had reached $93 \%$ (Amar et al. 2008). On Rota, the declines are not restricted to the crow but have occurred more widely; seven out of eight landbird species were found to have declined between 1982 and 1988, five species by more than 50\% (Amar et al. 2008). Unlike on Guam, these declines took place in the absence of the Brown Tree Snake, but nest predation and habitat loss are the two most likely candidates for the decline on Rota (Plentovich et al. 2005). Elsewhere in the Northern Mariana Islands, similar declines are also occurring amongst the endemic and restricted range species. For example, Nightingale Reed-warbler Acrocephalus luscinia densities on Saipan decreased by more than half between 1982 and 2007 (Camp et al. 2009). 
The population of the Mariana Crow has reached a critical juncture. Without intervention, this species will become extinct. For any declining species, it is essential to have a good understanding of the demography of the population so that conservation action can be appropriately targeted. This study uses mark-recapture techniques to estimate age-specific survival rates for the Mariana Crow population on Rota and uses these survival estimates, combined with published information on breeding success, to produce a series of models forecasting population trends. The outcomes of these models allow us to assess the future population size under varying assumptions of productivity, survival and population loss due to catastrophic events, such as typhoons, and removal of individuals for captive breeding.

\section{Methods}

\section{Survival analysis}

Between 1990 and 2010, 97 individual Mariana Crows were banded as fledglings and fitted with a combination of colour bands so they could be identified as individuals in the field. Estimates of survival and reporting rates were estimated using Cormack-Jolly-Seber (CJS) models in the program MARK (White and Burnham 1999), using RMark as an interface to build models. We tested for evidence of heterogeneity in the resighting histories of adult birds (i.e. $>1$ year old) using the program U-Care (Choquet et al. 2009) but found no evidence of transience or trapdependence. In the list of candidate models for survival, we included full time-dependence, linear or constant parameters with or without an age effect ( -1 year old and $1+$ years old, either as a factor or an additive effect). For reporting rate, a similar set of possible variables was used with the exception of linear effects. To estimate parameters, we used a model averaging approach to estimate each survival parameter for first-year and adult birds.

In addition, for a smaller set of known-sex birds ( $n=27$ males, 45 females), we ran CJS models to determine if there was a significant sex effect in survival rates. As the number of individuals banded and resighted was small, we did not run the whole suite of models performed for the allbird dataset but only tested whether the inclusion of a sex-factor improved the best fitting model from the all-bird dataset.

\section{Matrix model}

The mortality rates for each age class and sex from the CJS models were used in a deterministic matrix model to predict trends in population size. All simulations were based on a starting population of 330 birds (a best estimate based on previous work conducted during the late 1990s (US Fish and Wildlife Service 2005), including 110 pairs, plus 60 first-year birds and 50 secondyear birds. This produced a starting age structure that was distributed in a typical age pyramid, given that there is no information about the age structure of this population. Variables used in these experiments were age-specific mortality and fertility, and number of fledglings. Mortality values for each age class were those determined by the CJS analysis described above. Starting values for mean fertility (proportion of pairs producing nests) and number of fledglings per nest were determined by work conducted by Morton et al. (1999): we assumed that all three-year-old and older females bred, that $46.5 \%$ of breeding females produce one or more fledglings, and that if they fledge at all, they produce 1.2 fledglings on average.

Thus each year in the model included two columns, one for each sex, and 30 rows, one for each age class. The number of new fledglings of each sex (age class o) for each year was the result of multiplying the fertility ( $44 \%$ ) by the clutch size for fledglings for each sex (half of 1.2) times the number of pairs in each age class greater than two years old (the lesser of the number of males and females, since this is a monogamously-mating species). The number of males and number of females in each age class greater than zero was simply the number of birds of each sex respectively in the previous year and previous age class multiplied by the annual survival of that 
age and sex class. Both sex columns were summed to estimate the annual population. The spreadsheet was repeated to predict the number of crows alive after the $2 \mathrm{O}^{\text {th }}$ year, and also the number of years to extinction, in the case of a declining population. From this matrix, we were also able to calculate lambda, the intrinsic rate of population growth, and the standard error for lambda estimates, based on the values over 20 years.

\section{Simulations involving removal of birds}

A second scenario, referred to as the REMOVAL experiments, was run with the original starting variables but involved removals of fledglings in certain years to predict how a catastrophic event or nest removals for captive breeding would affect the future population. For the first removal experiment (REMOVAL-A), 20 fledglings, or birds at age zero, were removed in year 1 . In addition, eight birds were subtracted from the total fledgling population in years 2 and 3 . This removal in years 1-3 simulated the effects of the Guam Division of Aquatic and Wildlife Resources (DAWR) removals for captive breeding in the early 2000 .

The second removal experiment (REMOVAL-B) was run to simulate the effects of a repeated catastrophic event, specifically a typhoon. For this, half of the fledglings were removed from years 5 and 15 , simulating a total loss in productivity every 1o years due to a typhoon strike. Again, the outcome variable is the population size after 20 years. The third part to this experiment (REMOVAL-C) was run with both nest removals and a catastrophic event, a likely simulation for the real-world situation currently on Rota.

The third set of experiments (referred to as the SENSITIVITY experiments) involved a form of sensitivity analysis. Given that any set of realistic starting values predicted a dramatic population crash, we assumed the current (worst case) situation and asked what positive percentage change would be required in each of the model variables $\left(\mathrm{I}^{\text {st }}\right.$ year mortality, adult mortality, overall mortality, \% fledgling, and number fledged), taken individually, to produce a stable population of the size of the starting population (330 birds).

\section{Results}

\section{First-year and adult survival rates}

Using the all-birds dataset ( $n=97$ individuals), there was a large and rapid decline in the modelaveraged first-year survival from 0.7 to 0.4 and smaller decline in adult survival 0.86 to 0.82 over the 20 year study period (Figure $1 \mathrm{a}$ and $\mathrm{Ib}$; see Table $\mathrm{S}_{1}$ in the online Supplementary Material for all models considered). Resighting rates tended to be higher in the latter part of the study and the best fitting model had an additive reporting rate such that first-year reporting rates were higher than for adults (Figure $1 \mathrm{c}$ and $\mathrm{d}$ ). We were unable to find a significant difference between models containing a sex parameter and those without.

\section{Population modelling}

The starting population size for these models was 330 birds. Given the linear decline in first-year survival, we ran this model three times using first year survival rates of 0.80 (1991 estimate, Experiment 1a), 0.60 (approximate 2001 estimate, Experiment $\mathrm{Ib}$ ), and 0.40 (current estimate, Experiment Ic), and adult survival rates of 0.84 . Given these values, Experiment ra estimated a population size of 453 birds in 20 years (a growing population), Experiment $\mathrm{rb}$ estimated a population size of 218 birds in 20 years and predicted extinction of this population (i.e. less than one male and one female bird in the population) in 133 years, and Experiment $1 \mathrm{c}$ estimated a population size of 91 birds in 20 years and predicted extinction of this population in 75 years. The lambda for this last version of the model was $0.94 \pm 0.0014$, significantly less than one $(t=$ 42.86; df = 19; $P<$ o.001). 

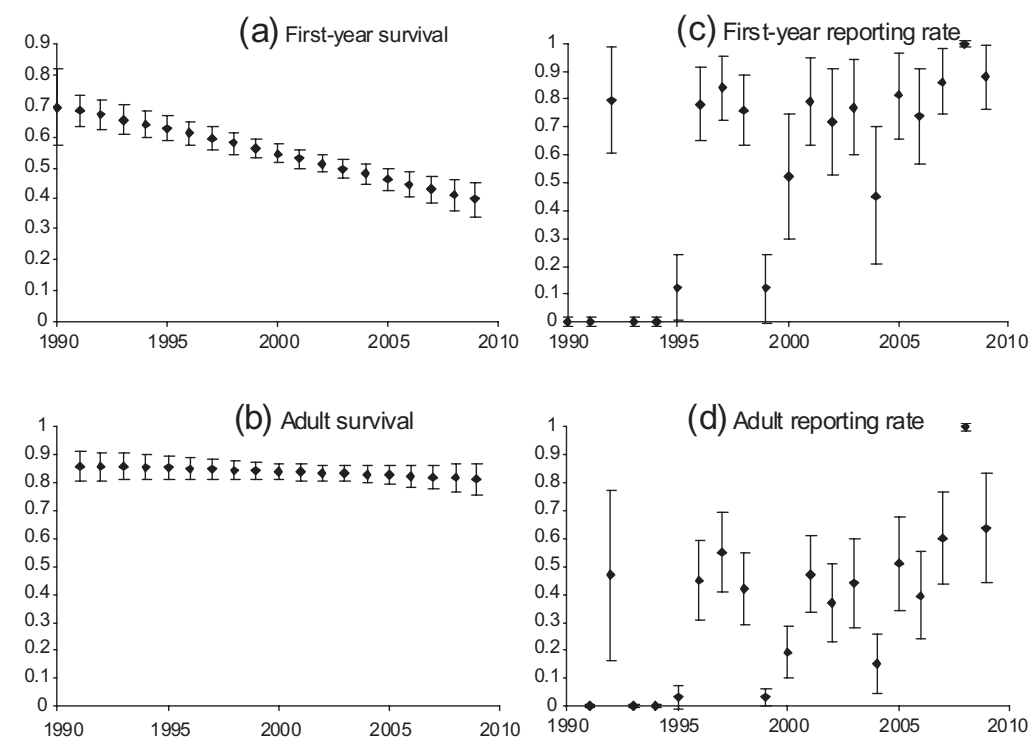

Figure 1 . Model averaged survival and reporting rates ( \pm SE) for Mariana Crows during (a and c) the first year of life and ( $b$ and $d)$ subsequent years.

The second set of experiments simulated the effects of losses from the population. For these models, we used the current estimate of first-year survival, o.40. The scenario where birds were removed in years $1-3$ for captive breeding (REMOVAL-A) resulted in an estimated population of 85 birds after 20 years, an additional decrease of $6.6 \%$ in the population. The second scenario simulated the effects of a repeated catastrophic event (REMOVAL-B), and this estimated a population of 83 birds after 20 years, a decrease of $8.9 \%$. The third part in which both nest removals and a catastrophic event were included (REMOVAL-C), estimated a population of 77 birds after 20 years, an additional decrease of $15.4 \%$. The lambda for this most extreme case was $0.94 \pm 0.0089(t=6.82, \mathrm{df}=19 ; P<0.0001)$.

In the SENSITIVITY modelling scenario, which asked to what degree initial values would have to change to produce a stable population of 330 birds after 20 years, results ranged from a $23 \%$ decrease in overall mortality (e.g. an improvement in both first year and adult survival from the current 40 and $84 \%$ to 54 and $88 \%$ ) to a $78 \%$ increase in the proportion of pairs successfully nesting or the number of birds fledged from successful nests (Table 1). Our estimates of the increase in survival or fecundity needed to achieve a stable population assumed no demographic or environmental stochasticity in our models and these estimates would be even larger if we had

Table 1 . The degree to which each individual demographic variable would have to change in order to produce a stable population of approximately the same size as the starting population (330 birds). Thus, to predict a population of 330 birds in 20 years, the value for $1^{\text {st }}$ year mortality would have to decrease by a factor of $0.52(52 \%)$, from a rate of 0.60 to a rate of 0.29 , without any changes in other variables from their initial values.

\begin{tabular}{lllll}
\hline Variable & Old Value & Factor & Direction & New Value \\
\hline 1st Yr Mortality & 0.60 & 0.48 & Decrease & 0.29 \\
2+ Yr Mortality & 0.16 & 0.45 & Decrease & 0.09 \\
All Mortality (1st/2nd+) & $0.60 / 0.16$ & 0.23 & Decrease & $0.46 / 0.12$ \\
Fertility (\% fledging) & .465 & 0.78 & Increase & 0.83 \\
Fledgling number & 1.2 & 0.78 & Increase & 2.14 \\
\hline
\end{tabular}


included stochasticity in a full population viability analysis (1977, Cohen 1979, Akçakaya et al. 2004, Whiting et al. 2008).

\section{Discussion}

The rapid decline in the Mariana Crow population on Rota has led to it being classified as "Critically Endangered" (IUCN 2008). The demographic causes for the decline are now better understood but the reasons for the doubling of first-year mortality (from 0.3 to 0.6 ) and slight decline in adult mortality are unknown but are sufficient to explain the observed population decline.

We compared the demographic rates of Mariana Crow with other declining and non-declining corvid populations. Five species of Corvidae were used for comparisons: two populations of American Crow Corvus brachyrhynchos (Caffrey 1992, Withey and Marzluff 2005), Alpine Chough Pyrrhocorax graculus (Delestrade and Stoyanov 1995), White-throated Magpie-jay Calocitta formosa (Langen 1996, Langen and Vehrencamp 1999), Florida Scrub-jay Aphelocoma coerulescens (Coulon et al. 2008) and Hawaiian Crow Corvus hawaiiensis (National Research Council 1992).

In general, a stable population was found to have a juvenile survival rate of around $70 \%$ (Alpine Chough 76.7\%; American Crow [California population] 68\%; American Crow [Seattle population] $45 \%$; White-throated Magpie-jay 64\%) compared with declining populations (Florida Scrub-jay $33.9 \%$; Hawaiian Crow 43\%). The exceptionally low value for the Seattle population of the American Crow was found to be due to emigration of the population out of the city and into the suburbs (Withey and Marzluff 2005). Over the past 20 years, first-year survival in the Mariana Crow has declined from $70 \%$ (similar to that of other stable corvid populations) to $40 \%$. Our sensitivity analyses also indicated that a stable population of Mariana Crows could be achieved with a first-year survival rate of $71 \%$, without any other changes in population demographics.

In terms of adult survival rates, stable populations were found to have adult survival rates around $90 \%$ (Alpine Chough, studied in two separate areas, $83 \%$ and 92\%, American Crow [California population] $97 \%$ for females and $93 \%$ for males; White-throated Magpie-jay $89 \%$ ) and declining populations had lower rates (Florida Scrub-jay $81.5 \%$ for males and $82.6 \%$ for females; Hawaiian Crow $70 \%$ ). The values for the Mariana Crow (a decline from $86 \%$ to $82 \%$ ) are the highest of these three species and adult mortality may be less of an issue for the Mariana Crows on Rota than for the (former) Hawaiian Crow population.

While we did not detect a significant difference in apparent survival rates between male and female Mariana Crows, there was a distinct lack of data to test this and we have not presented the analyses. Differences have been observed in other corvid populations. In Corvidae, it has often been found that one sex will disperse around one year of age while the other sex remains around their birth site and becomes a helper and this may account for the apparent differences in survival rates found between male and female birds. Behaviour observed in the Florida Scrub-jay and the American Crow of Seattle suggested that the female was the dispersing sex (Coulon et al. 2008, Withey and Marzluff 2005). It would be useful to test this hypothesis for Mariana Crows in the future to better understand the dynamics of this population.

We expected the survival rate of adult Mariana Crows to be similar to that of other declining corvid populations (Florida Scrub-jay and the Hawaiian Crow), and there were similarities (National Research Council 1992, Coulon et al. 2008). All three species have much lower firstyear survival rates than that of any stable population.

Clearly our most dramatic finding, and the cause of the rapid population decline, has been the dramatic decline in survival of first-year fledglings in this population, from a healthy value for related species of about $70 \%$ to a critically low value of $40 \%$. Our ongoing research has now incorporated radio-telemetry tracking of fledglings, and while our sample sizes are very small, we hope that we will soon be able to identify the sources of this loss. Initial findings point to feral cats and other ground predators as an issue. 


\section{Removal of chicks for captive breeding and the impact of catastrophic events}

The results generated by our model without the effects of nest removals and catastrophic events suggest that the Mariana Crow population has a strongly negative intrinsic rate of population growth, thus predicting (perhaps unsurprisingly) a further significant decline in the population over 20 years. Adding in the more realistic catastrophic events and simulating the 20-year effects of removal for captive breeding attempts suggested only a more rapid slide to extinction but only reducing the life of the wild population by a few years. Recent field surveys support this trend by showing that the current estimate of adults is about 160 (unpublished, 2008). As further confirmation of the validity of our population model, and based on a starting population of 330 birds as reported by Morton et al. (1999) and including fledgling removals and catastrophic (typhoon) effects, our model predicts a population of 164 adults at publication (2010), eleven years into the model run.

The sensitivity analysis suggested that the population was most sensitive to overall mortality rates, and then to adult mortality rates. The key change has been in first year survival. It would take enormous changes in the two fertility measures to have a significant impact on the population. These analyses were performed in a univariate manner, allowing the change in only one variable while others remained at their best-estimate levels. Future work should include more complex modelling which allows the simultaneous optimisation of multiple variables and the separation of mortality from emigration. In these more complex models, we will also incorporate variability into our modelling, taking a stochastic approach rather than a static deterministic approach. There are, of course, many assumptions that go into such modelling. We are using the best information that is currently available for age-specific mortality and fertility, and starting population size. One significant assumption is the age structure of the starting population: in this work, we have assumed a starting population of 330 birds, structured into age classes in a declining age pyramid fashion, reflecting the age-specific mortality data that we have generated in our mark-resight data analysis. But if the age structure differs significantly, and we really don't have good data on the current age structure, then the results of this model may be quite different.

\section{Conclusions}

This study has indicated and indeed reiterated that, without further intervention, the Mariana Crow is sliding rapidly towards extinction. Although the key demographic change causing the decline has been identified, the mechanisms underlying it have not. Future research should concentrate on fully understanding the causes of mortality and nest failure and putting in place conservation measures to combat these. Plentovich et al. (2005) identified predation and habitat loss as key causes for the decline of the crow on Rota and studies following the fate of nests using remote cameras and the fate of juvenile birds using radio-tags are urgently needed, and under way. Although further research is required, further intervention to prevent extinction needs to be urgently considered, including a rapid assessment of whether to, and when to, implement a captive-rearing programme and how to improve first-year survival in wild-bred birds.

\section{Supplementary Material}

The supplementary materials for this article can be found at journals.cambridge.org/bci

\section{Acknowledgements}

This manuscript would not have been possible without the mark-resight record contributions from numerous field biologists over the years, including but not limited to: Tino Aguon, Arjun Amar, Fred Amidon, Monica Awasthy, Lainie Berry, Melanie Colon, Blaine Dicke, Sarah Faegre, 
Shawn Farry, Phil Hannon, Mayumi Knight, Ken Levenstein, Blake Massey, John Morton, Sheldon Plentovich, Lauren Pulliam, Jeff Qutigua, Evan Rehm, Gabrielle Robinson, Dan Rollinson, Steve Seibel, Jarom Stanaway, Emily Weiser, and additional staff over the years from Guam's Division of Aquatic and Wildlife Resources. Phil Atkinson and Alison Johnson (British Trust for Ornithology) undertook the survival anlayses. We are grateful for the valuable reviews of earlier versions of this manuscript by Jeff Hatfield, Matt Geary and an anonymous reviewer. Jennifer Marsh provided the critical data entry and quality control. Laura Williams and Shelly Kremer provided logistical and funding support for our work in the CNMI. The authors would like to thank the Whiteley Center at Friday Harbor Laboratories, University of Washington, which provided support for writing this manuscript, and thank Miles and Jessica Bensky for contributing the initial literature review on corvids, which has been a great value to our on-going research project. Funding for this work was provided by the Commonwealth of the Northern Mariana Islands, Division of Fish and Wildlife, and U.S. Fish and Wildlife Service, Section 6 Endangered Species Grants.

\section{References}

Amar, A., Amidon, F., Arroyo, B., Esselstyn, J. A. and Marshall, A. P. (2008) Population trends of the forest bird community on the Pacific island of Rota, Mariana Islands. The Condor 110: 421-427.

Akcakaya, H. R., Burgman, M. A., Kindvall, O., Wood, C. C., Sjögren-Gulve, P., Hatfield, J. S. and McCarthy, M. A., eds. (2004) Species conservation and management: Case studies. Oxford, UK: Oxford University Press.

BirdLife International (2010) Species factsheets. Downloaded from http://www. birdlife.org/datazone/index.html on 20 October 2010.

Boyce, M. S. (1977) Population growth rate with stochastic fluctuations in the life table. Theor. Popul. Biol. 12: 366-373.

Caffrey, C. (1992) Female-biased delayed dispersal and helping in American Crows. The Auk 109: 609-619.

Camp, R. J., Pratt, T. K., Marshall, A. P., Amidon, F. and Williams, L. (2009) Recent status and trends of the land bird avifauna on Saipan, Mariana Islands, with emphasis on the Nightingale Reed-warbler Acrocephalus luscinia. Bird Conserv. Int. 19: 323-337.

Choquet, R., Lebreton, J.-D., Gimenez, O., Reboulet, A.-M. and Pradel, R. (2009) U-CARE: Utilities for performing goodness of fit tests and manipulating CApture-REcapture data. Ecography 32: 1071-1074.
Cohen, J. E. (1979) Comparative statistics and stochastic dynamics of age-structured populations. Theor. Popul. Biol. 16: 159-171.

Coulon, A., Fitzpatrick, J. W., Bowman, R., Smith, B. M., Makarewich, C. A., Stenzler, L. M. and Lovette, I. J. (2008) Congruent population structure inferred from dispersal behavior and intensive genetic surveys of the threatened Florida Scrub-Jay. Mol. Ecol. 17: 1685-1701.

Delestrade, A. and Stoyanov, G. (1995) Breeding biology and survival of the Alpine Cough. Bird Study 42: 222-231.

Fancy, S. G., Lusk, M. R., and Grout, D. (1999) Status of the Mariana crow population on Rota, Mariana Islands. Micronesica 32: 3-10.

IUCN (2008) IUCN Red List of threatened species. <www.iucnredlist.org>;. Downloaded on 04 November 2008.

Langen, T. A. (1996) The mating system of the White-throated Magpie-jay Calocitta formosa and Greenwood's hypothesis for sex-biased dispersal. Ibis 138: 506513.

Langen, T. A. and Vehrencamp, S. L. (1999) How White-Throated Magpie-Jay helpers contribute during breeding. The Auk 116: 131-140.

Morton, J. M., Plentovich, S. and Sharp, T. (1999) USFWS final report: Reproduction and juvenile dispersal of Mariana crows (Corvus kubaryi) on Rota 1996-1999. Honolulu: USFWS. 
National Research Council (U.S.) (1992) Scientific bases for the preservation of the $\mathrm{Ha}$ waiian Crow. Board on biology commission on life sciences national research council. Washington DC: National Academy Press.

Plentovich, S., Morton, J., Cramp, R., Bart, J., Lush, M. and Johnson, M. (2005) Population trends of the Mariana Crow Corvus kubaryi on Rota, Commonwealth of the Northern Mariana Islands. Bird Conserv. Int. 15: 211-224.

Savidge, J. A. (1987) Extinction of an island forest avifauna by an introduced snake. Ecology 68: 66o-668.

U.S. Fish and Wildlife Service. (2005) Draft revised recovery plan for the Aga or Mariana Crow, Corvus kubaryi. Portland, Oregon: USFWS.
White, G. C. and Burnham, K. P. (1999) Program MARK: Survival estimation from populations of marked animals. Bird Study 46 (Suppl.): 120-138.

Whiting, M. J., Dixon, J. R., Greene, B. D., Mueller, J. M., Thornton, Jr.O. W., Hatfield, J. S., Nichols, J. D. and Hines, J. E. (2008) Population dynamics of the Concho water snake in rivers and reservoirs. Copeia 2008: 438-445.

Williams, D. A. and Rabenold, K. N. (2005) Male-biased dispersal, female philopatry, and routes to fitness in a social corvid. $J$. Anim. Ecol. 74: 150-159.

Withey, J. C. and Marzluff, J. M. (2005) Dispersal by juvenile American Crows influences populations dynamics across a gradient of urbanization. The Auk 122: 205-221.

JAMES C. HA*, ALYSSA BUTLER, RENEE ROBINETTE HA

Department of Psychology, University of Washington, Box 351525, Seattle WA 98195.

*Author for correspondence; e-mail: jcha@u.washington.edu

Received 5 November 2008; revision accepted I May 2009 